\title{
Gender Equality in the Academy: The Pipeline Problem
}

Kristen Renwick Monroe, University of California, Irvine

William F. Chiu, University of California, Irvine

On behalf of the Committee on the Status of Women in the Profession

ABSTRACT As part of the ongoing work by the Committee on the Status of Women in the Profession (CSWP), we offer an empirical analysis of the pipeline problem in academia. The image of a pipeline is a commonly advanced explanation for persistent discrimination that suggests that gender inequality will decline once there are sufficient numbers of qualified women in the hiring pool. The CSWP believes that it is important to ask whether this phenomenon is actually occurring, because the implication is that we can explain inequality as a function of insufficient numbers of trained women in the pool, rather than as a result of ongoing discrimination that requires alternate remedies. Data from the American Association of University Professors suggests that merely increasing the pool of qualified women has not led to a commensurate number of women rising to the top in academia. Women are still ending up in lower paid jobs, and they continue to earn less than men in comparable positions. More aggressive policies to end discrimination are required.

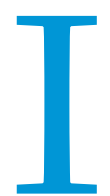

s gender equality a dead political issue? The political campaigns of Hillary Clinton and Sarah Palin in the 2008 U.S. presidential election indicate otherwise. Charges were levied that the women faced differential standards for report-

age and candidate evaluation, and the charges themselves then became contentious. If bias cleaves along gender lines, discrimination should logically extend beyond politics into the workplace at large, including academia. It takes a particular blend of moral courage and integrity to examine inequities in one's own house, and university administrators have a mixed record in responding to examinations of gender equality in academia. Presidents such as Charles Vest at the Massachusetts Institute of Technology (MIT) have embraced the examination, even when it revealed ongoing discrimination among his faculty. Not all university presidents have demonstrated such admirable responses, however, with too many administrators feeling criticized and responding defensively rather than acknowledging the problem and working creatively to solve it. Female college presidents have

Kristen Renwick Monroe is a professor of political science and philosophy and director of the Interdisciplinary Center for the Scientific Study of Ethics and Morality at the University of California, Irvine. A past president of the International Society of Political Psychology, Dr. Monroe is an expert on altruism and its implications for social and moral theory. She can be reached at krmonroe@uciedu.

William F. Chiu is a Ph.D. candidate in political science with an emphasis in political psychology at the University of California, Irvine. His thesis examines political communication and speech on the Internet. He holds degrees from Georgetown University and the University of California, Berkeley. He can be reached at williamchiu@cox.net. been noteworthy for their approaches, and several of these women were highlighted at the 2008 APSA Panel sponsored by the Committee on the Status of Women in the Profession (CSWP), including presidents Carol Christ (Smith College), Amy Gutmann (University of Pennsylvania), Nannerl Keohane (Wellesley College and Duke University), and Dale Rogers Marshall (Wheaton College). The importance of positioning women in university presidencies illustrates one of the most frequently advanced solutions for gender discrimination: get qualified women in the pipeline and they will naturally work their way to the top, where their unique experiences will lead to policies that will end gender discrimination. Although there is some truth, and certainly many nuances to this position that could be discussed, here we focus on one particular aspect of the pipeline argument: the belief that gender inequality will decline once there are sufficient numbers of qualified women in the pool. It is important to ask whether this phenomenon is in fact occurring, because the implication of the pipeline argument is that we can explain inequality as a function of insufficient numbers of trained women in the pool, rather than as a result of ongoing discrimination that requires alternate remedies.

The CSWP examined the pipeline argument using an analysis of aggregate data from the American Association of University Professors (AAUP). This article summarizes a more complex and thorough analysis (Chiu and Monroe 2010) that confirms prior University of California, Irvine, and MIT findings using qualitative interview data to conclude that discrimination continues in 
Table 1

\section{Graduate School Enrollment and Doctoral Degree Attainment 2006}

\begin{tabular}{lc|cc}
\multicolumn{2}{c|}{$\begin{array}{c}\text { GRADUATE ENROLLMENT } \\
\text { (\%) }\end{array}$} & \multicolumn{2}{c}{$\begin{array}{c}\text { DEGREE ATTAINED } \\
\text { (\%) }\end{array}$} \\
\hline Women & Men & Women & Men \\
\hline 54 & 46 & 48 & 52 \\
\hline
\end{tabular}

Source: Council of Graduate Schools 2007

Table 2

Male and Female Share of Academic Ranks

ALL INSTITUTIONS

PERCENTAGE OF FACULTY (\%)

\begin{tabular}{l|cc}
\hline Rank & Men & Women \\
\hline Professor & 23.5 & 8.2 \\
\hline Associate Professor & 15.9 & 10.8 \\
\hline Assistant Professor & 14.1 & 13.2 \\
\hline Lecturer & 2.8 & 3.4 \\
\hline All & 59.7 & 40.3
\end{tabular}

Source: American Association of University Professors 2008

Table 3

Percentage of Faculty, by Track and Gender

\begin{tabular}{l|cc}
\multirow{2}{*}{ FACULTY TRACK } & \multicolumn{2}{|c}{ PERCENT OF COHORT (\%) } \\
\cline { 2 - 3 } & Men & Women \\
\hline Tenure & 60.0 & 41.6 \\
\hline Tenure-Track & 21.1 & 26.2 \\
\hline Nontenure & 18.9 & 32.2 \\
\hline
\end{tabular}

academia. National statistics clearly show that there are fewer American women working in academia than expected, given the relatively comparable numbers of female graduate students entering the market now. Further, women are employed at lower status institutions and ranked at lower grades in the same institutions, and they earn less at each grade compared to their male counterparts. An examination of alternate explanations-other than discrimination-finds these reasons unconvincing and unconfirmed by the aggregate data. The data thus suggest the existence of a glass ceiling that manifests itself as a filter at the highest rank and levels of prestige. Women participate at deteriorating levels as ranks rise at colleges, universities, and research institutions. At the highest level-the research I institution-women constitute $10.9 \%$ of assistant professors but only $7.2 \%$ of full professors. This disparity in numbers between men and women is both striking and extremely troubling, because the aggregate data suggest that this disparity represents a problem of advancement and not an absence of qualified female candidates. Space constraints limit the material we can present here, and much of the nuance is lost in an overview; nonetheless, tables 1 through 9 demonstrate the problem with assuming that simply increasing the pool of qualified women will end discrimination.
Essentially, income inequality within an institutional class does not appear to worsen on a per capita basis; at a given level, the gap in pay for men and women appears constant. But the type of institution in which women find work and the differential curves that attach to each type reveal stark differences in career slope (see figure 1) between the community college and research university levels. The aggregate statistics presented in tables 4-7 and figure 1 suggest the glass ceiling in academia is not merely one barrier at the very top of academia but instead exists as a sorting mechanism throughout the academic workplace. Note the differentials in employment density in tables 4 and 5 , the differentials in gross pay in table 6 and the average pay within grade for men and women in table 7. Because the percentage of women in the pool of professors has increased since the 1980 os without comparable improvement in the percentage of women in the professoriate, the pipeline approach will not fix this gender inequity. More focused and systematic policies are required.

Our analysis thus substantiates other studies using aggregate data, which find both wage and hiring differentials (NSF Science and Engineering Indicators 2008) and a glass ceiling (Cotter et al. 2001) in the academy. Scholars also find surprising gender bias in more focused assessments of worth, such as the differential evaluations of academic citations (Johnson 1997) and the peer review process (Wenneras and Wold 1997). Women are cited less than men and suffer from gender bias in the review process itself, with experimental tests revealing bias in evaluations of the same work, depending on whether the author is listed as a man or a woman. Both these experimental tests and extensive in-depth interview data with female faculty at MIT $(2002 ; 1999)$ and the University of California, Irvine (Monroe et al. 2008), offer more detailed systematic evidence that gender equality in academia remains only a partially realized goal, with women still struggling to crack a glass ceiling that remains strong and oppressive for all but a fortunate few.

What is the implication of these studies? More active policies by university administrations and professional societies-such as APSA-are required to eliminate gender inequality in the academy.

\section{OVERVIEW OF FULL ANALYSIS}

Given the standard set forth in Title IX, equity in outcomes is not just economically optimal (Becker 1971) or socially desirable, but also legally necessary. Our full analysis begins with the important Title IX, which creates a legal overhang of punishment for transgression. Interpreted using the standard rational actor logic of economics, a rational individual would not discriminate because of the disincentives and penalty of litigation and punishment. Developed further, one might assume that compliance is the conventional practice and discrimination the outlier. Accepting such a premise, one might search for some other explanation for the gender equity gap in academic wages and placement. The pipeline argument, in which the constitution of the workplace reflects the output over time of a stream of trainees, offers a palliative by which disproportions are remedied incrementally as talented individuals of a particular ascriptive characteristic-gender, race, or ethnicity, for example-enter the workforce. In addition, the pipeline solution suggests that problems such as tokenism and status expectations will be ameliorated naturally. As the number of women increases, sheer numbers and forced social contact should mitigate stratification based on homophily (i.e., preference for same gender), segregated social networking and mentoring, and 
Percent of Faculty, by Academic Rank at Major Institutions and by Gender

\begin{tabular}{|c|c|c|c|c|c|c|c|c|}
\hline \multirow[b]{2}{*}{ RANK } & \multicolumn{2}{|c|}{$\begin{array}{c}\text { DOCTORAL } \\
\text { (RESEARCH INSTITUTIONS; \%) }\end{array}$} & \multicolumn{2}{|c|}{$\begin{array}{c}\text { MASTER'S } \\
\text { (UNIVERSITIES; \%) }\end{array}$} & \multicolumn{2}{|c|}{$\begin{array}{l}\text { BACHELOR'S } \\
\text { (COLLEGES; \%) }\end{array}$} & \multicolumn{2}{|c|}{$\begin{array}{c}\text { TWO-YEAR } \\
\text { (COMMUNITY COLLEGES; \%) }\end{array}$} \\
\hline & Men & Women & Men & Women & Men & Women & Men & Women \\
\hline Professor & 28.1 & 7.2 & 19.6 & 8.3 & 19.8 & 9.2 & 15.7 & 14.0 \\
\hline Associate Professor & 16.4 & 9.8 & 15.6 & 11.5 & 16.4 & 12.5 & 11.5 & 11.4 \\
\hline Assistant Professor & 13.4 & 10.9 & 14.7 & 15.1 & 15.6 & 16.5 & 12.5 & 14.4 \\
\hline Instructor & 2.1 & 3.1 & 2.4 & 4.1 & 2.8 & 4.1 & 7.7 & 9.3 \\
\hline Lecturer & 3.3 & 3.9 & 3.0 & 3.8 & 1.0 & 1.1 & 1.4 & 1.9 \\
\hline Other & 0.9 & 1.0 & 0.9 & 0.9 & 0.5 & 0.5 & 0.1 & 0.2 \\
\hline Overall & 64.2 & 35.9 & 56.2 & 43.7 & 56.1 & 43.9 & 48.9 & 51.2 \\
\hline
\end{tabular}

Note: Total faculty sizes: doctoral (research institutions), $n=178,584$; master's (universities), $n=118,557$; bachelor's (colleges), $n=50,557$; two-year (community colleges), $n=19,778$.

Table 5

Type of Employing Institution, by Gender

\begin{tabular}{lcc} 
INSTITUTION TYPE & $\begin{array}{c}\text { MEN } \\
(\%)\end{array}$ & $\begin{array}{c}\text { WOMEN } \\
(\%)\end{array}$ \\
\hline Research & 52.3 & 43.2 \\
\hline University & 30.4 & 35 \\
\hline College & 12.9 & 15.0 \\
\hline Two-Year College & 4.4 & 6.8 \\
\hline
\end{tabular}

Source: American Association of University Professors 2008

Table 6

Women's Average Salary as a Percentage of Men's, by Rank and Institution

\begin{tabular}{lcccc} 
RANK & $\begin{array}{c}\text { RESEARCH } \\
\mathbf{( \% )}\end{array}$ & $\begin{array}{c}\text { UNIVERSITY } \\
\mathbf{( \% )}\end{array}$ & $\begin{array}{c}\text { COLLEGE } \\
\mathbf{( \% )}\end{array}$ & $\begin{array}{c}\text { COMMUNITY } \\
\mathbf{( \% )}\end{array}$ \\
\hline Professor & 91.0 & 94.9 & 95.3 & 96.4 \\
\hline Associate Professor & 92.3 & 95.8 & 97.8 & 97.3 \\
\hline Assistant Professor & 92.0 & 96.0 & 97.6 & 98.0 \\
\hline Overall & 78.2 & 87.6 & 89.8 & 95.3 \\
\hline
\end{tabular}

the tendency to characterize success and authority in masculine terms (Roth 2004). Finally, one might suppose that a rich pipeline of qualified individuals would ultimately result in women rising to the top over time, thus breaking the glass ceiling naturally and without requiring specific policies to end gender discrimination. A concomitant hypothesis is that inequitable pay today is a snapshot of past asymmetries in human talent that have persisted over time, rather than discrimination practiced on individuals today.

On its surface, the pipeline argument is appealing-what goes in must come out, and today's accomplished senior faculty reflect yesterday's narrow pool. If the entrance to the pipeline is based purely on choice and more men have chosen to enter it than women, then the gender gap is a reflection of aggregate individual will, rather than systematic bias. Closer inspection, however, reveals flaws of omission in this analysis. The pipeline is not lossless-individuals who enter might drop out as a result of sys- temic patterns of bias in the mentoring faculty pool-and it extends beyond degree-granting programs into tenure-track and advancement programs, describing a career trajectory rather than a pipeline that is demarcated arbitrarily at the point of earning a Ph.D.

What explains the patterns in employment rank and pay at the major higher education tiers? Studies of academic and commensurate private sector and federal jobs indicate that a larger pipeline does not lead to more women in higher status positions, given the problems in the advancement mechanism (Myers and Turner 2004; Roth 2004; Powell and Butterfield 1997). If mentoring is one key to advancement, the lack of women in a position to mentor leads to inferior group results for women, as compared to men (Smeby 200o). Such reports suggest that a closer look at the pipeline is warranted prior to accepting it as an explanatory frame for gender patterns in the academic marketplace.

We thus examined pipeline arguments to determine whether gender discrimination in academia is being corrected as more women enter the graduate school pool and move through the system. Our analysis uses aggregate data collected by the AAUP on the status of women in higher education in the United States over (roughly) the last 30 years-years that saw increased efforts to expand the pool of women entering the academic market. Analysis of these data suggests that the percentage of women in the academy remains disproportionately low, and that those women who do succeed in finding an academic job, as well as women overall, still earn less for the same job than their male counterparts. The pattern in academia thus reflects the male/female wage gap that has characterized the U.S. economy since analysts began tracking such data in the 1970 .

The questions then become: Why does this pattern exist? Does this pattern represent ongoing discrimination? Part I of our full study outlines the legal and economic context for our analysis. In particular, we ask if there are explanations (Becker 1971) other than discrimination that might account for differential treatment of male and female faculty. Part II analyzes these economic explanations using AAUP data and finds no economic explanation that can fully explain the gender gap. The persistence of ongoing, if subtle, gender discrimination remains the far more plausible explanation. A fairly extensive aggregate analysis of statistical data on gender discrimination within academia thus confirms the results of the more impressionistic, interview data presented in the University of California, Irvine, and MIT studies. Glass ceilings 


\section{Table 7}

Percentile Scale of Average Salary, by Gender, Rank, and Institution Type

\begin{tabular}{l|ccc|cc|cc|cr} 
PERCENTILE RANK & \multicolumn{2}{|c|}{ DOCTORAL } & \multicolumn{2}{c|}{ MASTER'S } & \multicolumn{2}{c|}{ BACHELOR'S } & \multicolumn{2}{c}{ TWO-YEAR } \\
\hline Rank & \multicolumn{2}{|c|}{ Men } & Women & Men & Women & Men & Women & Men & Women \\
\hline Professor & 62 & 49 & 61 & 54 & 59 & 53 & 56 & 51 \\
\hline Associate Professor & 67 & 51 & 60 & 49 & 57 & 51 & 53 & 46 \\
\hline Assistant Professor & 66 & 53 & 66 & 61 & 60 & 52 & 50 & 50 \\
\hline
\end{tabular}

women are employed at lower status institutions. Women are ranked at lower grades, and they earn less at each grade compared to their male counterparts. We have tried to scrupulously and objectively examine possible explanations for these realities other than discrimination, but we find these explanations unconvincing and unconfirmed by the aggregate data. Why would a woman fail to enter the academy after earning a costly doctoral degree? Under a human capital argument, it defies economic logic for a woman to expend such effort in time and money to earn a credential and then not seek full financial

Table 8

Comparison of University of California, Irvine, Academic Salaries for a Given Rank and Step, by Field

\begin{tabular}{|c|c|}
\hline & PROFESSOR-STEP III \\
\hline Regular & $\$ 95,000$ \\
\hline Business/Economics/Engineering & $\$ 109,500$ \\
\hline Health Sciences & $\$ 135,600$ \\
\hline \multicolumn{2}{|c|}{$\begin{array}{l}\text { Source: University of California, Irvine, Department of Academic Personnel } 2009 \text {. } \\
\text { The University of California operates on a step system, in which faculty are hired as } \\
\text { an assistant professor (step 1) and then advance up the steps in one category } \\
\text { before advancing to the next category (e.g., associate professor). Step } 3 \text { denotes a } \\
\text { full professorship. }\end{array}$} \\
\hline
\end{tabular}

recompense. No rational person would work so hard for such meager gain; indeed, one would surmise that the commitment to an academic career is tested in the graduate school process, and that less-committed people would drop out. Survivors thus should thrive precisely because they have demonstrated deeper commitment. Yet women, who comprise nearly half of all doctoral degree conferees, suffer an attrition rate of nearly one in six and constitute only $40 \%$ of professors.

If there is a glass ceiling, it would manifest itself as a filter at the highest rank and level of prestige. Our analysis finds that women do, in fact, participate in the academy at deteriorating levels as ranks rise at colleges, universities, and research institutions. At the highest level-the research I institution-women constitute $10.9 \%$ of assistant professors but only $7.2 \%$ of full professors. This disparity in numbers between men and women is both striking and extremely troubling, since - as the aggregate data suggestthis disparity represents a problem of advancement and not an absence of candidates. Income inequality within an institutional class does not appear to worsen on a per capita basis; at any given level, the gap in pay for men and women appears constant. The shape and slope of the curves in figure 1 show that female and male professors at research institutions appear to track similar rates of remuneration as their are multiple and resilient. Worse, analysis suggests gender inequality will not be alleviated significantly through the natural projection of more women into the pool of graduate school. More positive efforts will be necessary to end gender inequality in academia.

\section{CONCLUSION}

We know that gender inequality exists as a political problem in much of the world, but how promising is the situation for women within the American academy itself? Aggregate statistics confirm the discouraging view of gender equality gleaned from interview data about the situation for women in academia (Massachusetts Institute of Technology [MIT] 1999; MIT 2002; Monroe et al. 2008). An evaluation of the big picture enhances our view into the material context in which female faculty operate. National statistics clearly show that fewer women work in academia than would be expected, given the relatively comparable numbers of male and female graduate students currently entering the market. Overall, rank increases; however, note that the curve for women is shifted markedly lower compared with that for men. The gaps reveal that women consistently earn $3 \%$ to $8 \%$ less than men. Is the gap a result of human capital or bias? At what differential does the academy need to pursue more granular study?

In addition, our comparison of institutional classes underscores the striking disparity in pay. As women move from lower to higher ranking institutions, pay inequalities increase. A $3 \%$ average gap at the community college level becomes an $8 \%$ percent gap at the research I institution level. Understanding the job placement system in academia as a whole may shed light on the distribution of jobs in the industry. The labor market is segmented into two broad categories: jobs with and without long-term security. It is further stratified into many small niches of expertise in departments, fields, subfields, and specialties. The nature of teaching and research distinguishes the advancement process in academia from the private sector through the tenure system, which 


\section{Figure 1}

\section{Trajectory of Average Wage, by Rank and Institutional Type}

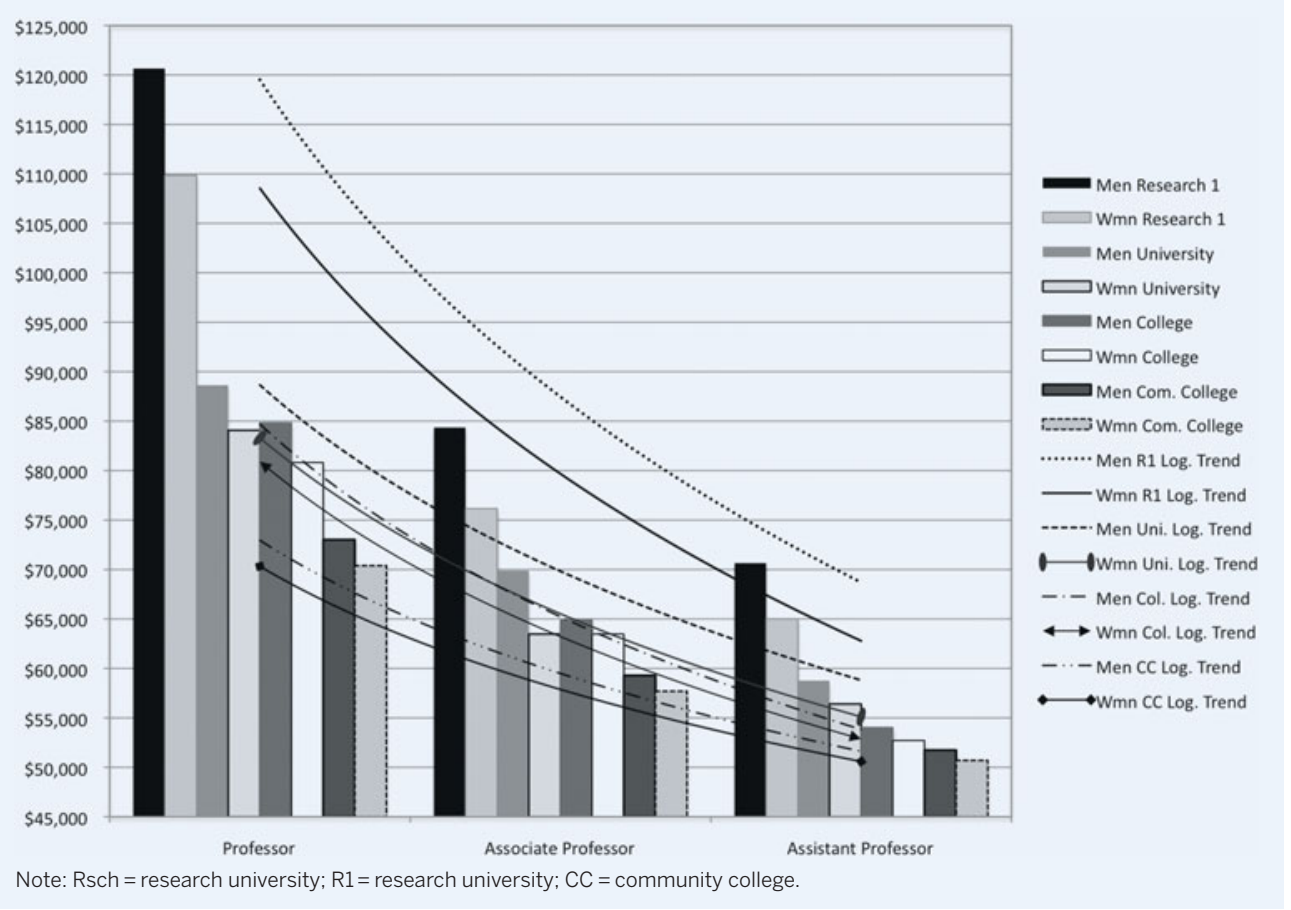

down in prestige further appears to lead to a statistically significant increase or decline in productivity (Allison and Long 1990). Tenure differentiates academia from the private sector, because tenure track positions require a large commitment in time. Moreover, tenure status is not easily transported, because higher education is not an open labor market. A tenure-track position is an invitation to a long-term association. All of these characteristics make the importance of the first job quite significant. Although no one has conducted such an exercise for academia, estimates from the private sector market suggest a professional woman loses an average of $\$ 1$ million over a lifetime of employment, merely by failing to successfully negotiate the terms of her first position (Babcock and Lavescher 2003).

The nature of voting rules safeguards the freedom to pursue knowledge. What if tenure operates as an early gate that constrains career trajectory at entry?

Tenure-track employees are not "at-will" and cannot easily be fired or furloughed. Here we need to acknowledge the operational context of the university. As an economic entity, the university must balance economic priorities such as cost-control and costcertainty. Management of the labor pool is driven by academic and economic interests. Given the inflexibility of tenure jobs, the university may well offer a mix of jobs that enables it to maintain overall labor flexibility. Some candidates are offered tenure-track positions, others lectureships. This mix may manifest itself systemically as a filter system that channels women to various locations in the university hierarchy. More important, if gates between institutional levels are one-way, then a person who starts out at a lesser organization is likely to be confined to advancement at that level. In this vein, two indicators may show more clearly how the glass ceiling manifests itself in the academy. The head-count data displayed in table 4 indicate the operation of a quota system: men are overrepresented and, as a group, earn the lion's share of available income. This also can be seen in the individual-level data, which show that women earn $90 \%$ of the amount that men earn on a per capita basis, but collectively earn $21 \%$ less.

Where women go at the critical juncture of selecting institution type matters a great deal, and the differential curves that attach to each type show the slope difference between a community college and the research university level. As figure 1 details, the slope indicates pay difference. Women in economics, for example, are significantly less likely than men to earn tenure at their first academic job (Ginther and Kahn 2004). A slower launch into a career produces a shallow trajectory that results in impaired compensation over the duration. Location of hiring also matters, because prestigious universities may provide improved conditions for publication, which in turn lead to greater material benefits. A move up or may also act as a filter: senior faculty promote junior faculty to their ranks. Although this process is opaque, one can imagine that the reasoning behind elevation and compensation decisions may be affected by implicit or even explicit discrimination. The elevation of a candidate necessarily involves subjective as well as objective metrics. If tenured and senior male faculty interact with junior and scarce female colleagues, interaction may follow archetypes described by theories of tokenism (Kanter 1977) and a fundamental disconnect in lived experiences in the workplace (Hale 1999). For women with multiple roles-be they ethnic, gender, or familial-the proportion of women of multiple marginalities in a given workplace environment (i.e., when compared with white men or women) also affects perceptions and demands in the professional sphere (Turner 2002). The role of women in governance may affect the procedures instituted for advancement (Moore 1987). Whether systematic patterns that favor men over women guide advancement or individual consideration results in unintended collective gender bias cannot be known without further investigation. Given the confidentiality of tenure and promotion, we can only surmise the types of practices that are extant. But the aggregate statistics presented here suggest the glass ceiling in academia is not one barrier at the very top of academia, but instead exists at many levels throughout the academic workplace. ${ }^{1}$ Because the percentage of women in the pool of professors has increased since the 1980 s without comparable improvement in the percentage of women in the professoriate, the pipeline will not fix this gender inequity.

Finally, the overhanging presence of Title IX must not deter administrators from tackling this issue for fear of litigation. Interview data suggest countenancing this is a serious problem, with litigation-shy administrators fearful of acknowledging the existence of gender discrimination because it leaves them liable to lawsuits. The result of this reluctance is too often a cumbersome 
bureaucracy that was established to protect against discrimination but ultimately protects the institution against claims of discrimination. Collegiality, meritocracy, and common endeavor should guide the academy to act on the spirit of Title IX in proactively addressing inequity. More focused and systematic policies are required to end discrimination.

\section{NOTE}

1. We find it debatable whether women choose a job based on an estimation of the level of female domination within a particular subsector. If long-term earning potential is depressed at a college or community college, economic logic alone makes it unlikely that, given a research I alternative, a woman would choose these sectors, even if they are paid at a rate equal to that of men. All things being equal, it seems logical that a choice to take a job at a college or a university is as much exogenous as endogenous. If research universities set criteria that women cannot easily meet-because they are raising children or caring for elderly family members, for example-then structural impediments constrain their array of choices, and they are forced to select from a subset of men's choices. If women choose a community college because they care less about money and more about nonmonetary compensation, then college jobs may prove appealing. But when one considers the advantages-higher pay, higher status, and less classroom time, all of which result in the increase in individual freedom provided by a research university-it seems illogical that women would deliberately choose community college positions for family reasons. This is not to deny that work conditions can be construed in more than monetary terms. For academics, the resource pool that is on tap, in terms of colleagues, students, graduate programs, libraries, and facilities, among other factors, may be of equal or greater importance than a salary. On a basic level, the desire to work at the university level and above may simply act as an aspiration to actualize one's intellectual ambition. The economic data reveal a system that distributes monetary rewards unevenly, but the loss to the academic community may be greater than the loss to the individual. As a teacher, icon, role model, and mentor, a professor offers guidance to future generations of workers and leaders, scholars and professionals. The voice as a function of critical mass may thus be silenced if, at the highest levels, one group dominates another.

\section{REFERENCES}

Allison, Paul, and J. Scott Long. 1990. "Departmental Effects on Scientific Productivity." American Sociological Review 55: 469-78.

American Association of University Professors. 2008. "The Annual Report on the Economic Status of the Profession, 2007-08." http://www.aaup.org/AAUP/ comm/rep/Z/ecstatreport2007-08/survey2007-08.htm (accessed April 20, 2008).

Babcock, Linda, and Sara Lavescher. 2003. Women Don't Ask: Negotiations and the Gender Divide. Princeton: Princeton University Press.

Becker, Gary. 1971. The Economics of Discrimination. Chicago: University of Chicago Press.
Chiu, William, and Kristen Monroe. 2010. "Gender Equality and the Pipeline Problem in Academia." Under review.

Cotter, David, J. Hermsen, S. Ovadia, and R. Vanneman. 2001. "The Glass Ceiling Effect." Social Forces 80: 655-82.

Council of Graduate Schools. 2007. Graduate Enrollment and Degrees: 1996-2006. http://www.cgsnet.org/portals/o/pdf/DataSources_2008_03.pdf (accessed April 20, 2008)

Ginther, Donna, and Shulamit Kahn. 2004. "Women in Economics: Moving Up or Falling Off the Academic Career Ladder?" Journal of Economic Perspectives 18 (3): 193-214

Hale, Mary. 1999. "He Says, She Says: Gender and Worklife." Public Administration Review 59: 410-24.

Johnson, Dan. 1997. "Getting Noticed in Economics: The Determinants of Academic Citations." American Economist 41: 43-52.

Kanter, Rosabeth. 1977. "Some Effects of Proportions on Group Life: Skewed Sex Ratios and Responses to Token Women." American Journal of Sociology 82 (5): 965-90.

Massachusetts Institute of Technology (MIT). 1999. "A Study on the Status of Women Faculty in Science at MIT." http://web.mit.edu/faculty/reports/sos.html (accessed August 10, 2008).

. 2002. "A Study on the Status of Women Faculty in Science at MIT: 2002 Update of 1999 Study." http://web.mit.edu/faculty/reports/sos.html (accessed September 1, 2008).

Monroe, Kristen, Saba Ozyurt, Ted Wrigley, and Amy Alexander. 2008. "Gender Equality in Academia: Bad News from the Trenches and Some Possible Policy Solutions." Perspectives on Politics 6: 215-34.

Moore, Kathryn. 1987. "Women's Access and Opportunity in Higher Education: Toward the Twenty-First Century." Comparative Education 23: 23-34.

Myers, Samuel, and Caroline Turner. 2004. "The Effects of Ph.D. Supply on Minority Faculty Representation.” American Economic Review 94: 296-301.

National Science Foundation. 2008. "Science and Engineering Indicators 2008." http://www.nsf.gov/statistics/seindo8/pdfstart.htm (accessed May 19, 2009).

Powell, Gary, and D. Anthony Butterfield. 1997. "Effect of Race on Promotions to Top Management in a Federal Department." Academy of Management Journal 40: $112-28$.

Roth, Silke. 2004. "Opportunities and Obstacles-Screening the EU Enlargement Process from a Gender Perspective." Loyola University Chicago International Law Review 2 (1): 117-27.

Smeby, Jens-Christian. 200o. "Same Gender Relationships in Graduate Supervision." Higher Education 40: 53-67.

Turner, Caroline Sotello Viernes. 2002. "Women of Color in Academe: Living with Multiple Marginality.” Journal of Higher Education 73: 74-93.

University of California, Irvine, Department of Academic Personnel. 2009. "Academic Salary Scales." http://www.ap.uci.edu/salary/index.html (accessed October 10, 2009).

Wenneras, Christine, and Agnes Wold. 1997. "Nepotism and Sexism in PeerReview." Nature 387: 341-43. 